\title{
Rewarming rates and thermogenesis in hibernating echidnas 2 ?
}

\author{
Stewart C. Nicol* ${ }^{*}$ Niels A. Andersen \\ Anatomy and Physiology, University of Tasmania, Private Bag 24, Hobart, TAS 7001, Australia
}

Received 5 April 2006; received in revised form 15 August 2006; accepted 18 August 2006

\begin{abstract}
We measured body temperatures $\left(T_{\mathrm{b}}\right)$ in 14 free-ranging echidnas (Tachyglossus aculeatus) using implanted data-loggers. An average of $1020 \pm 744$ days of $T_{\mathrm{b}}$ data was recorded from each animal. The average maximum $T_{\mathrm{b}}$ was $35.3 \pm 0.7{ }^{\circ} \mathrm{C}(n=14)$, and the lowest $T_{\mathrm{b}}$ was $4.7^{\circ} \mathrm{C}$. Detailed analysis of rewarming events from four echidnas showed rewarming time to be dependent on initial $T_{\mathrm{b}}$ (rewarming time in hours $=15.6-0.41 T_{\text {initial }}, n=31$ ) with an average rewarming rate of $1.9 \pm 0.4{ }^{\circ} \mathrm{C} \mathrm{h}^{-1}$. Based on an hourly sampling rate, the peak rewarming rate was found to be $7.2 \pm 0.8{ }^{\circ} \mathrm{C} \mathrm{h}^{-1}(n=12)$, which was measured at a mean $T_{\mathrm{b}}$ of $26.2 \pm 2.4{ }^{\circ} \mathrm{C}$. This rate of heating was calculated to be equivalent to a peak oxygen consumption rate of $1.4 \pm 0.2 \mathrm{ml} \mathrm{O}_{2} \mathrm{~g} \mathrm{~h}^{-1}$, approximately 9 times the basal metabolic rate. We found that a plot of rate of change of $T_{\mathrm{b}}$ against $T_{\mathrm{b}}$ for the entire data set from an individual echidna provided a useful summary and analytical tool.
\end{abstract}

(c) 2006 Elsevier Inc. All rights reserved.

Keywords: Tachyglossus aculeatus; Echidna; Monotreme; Hibernation; Thermoregulation; Rewarming; Maximal metabolic rate; Non-shivering thermogenesis

\section{Introduction}

When first described in the scientific literature, hibernation in the egg-laying echidna was interpreted as a confirmation that this was a primitive mammal "lowest in the scale of warmblooded animals" and an incomplete homeotherm that during cold weather "abandons all attempts at homeothermism" (Martin, 1902). Since that time it has become apparent that hibernation is not simply a matter of abandoning the control of body temperature, but is under precise physiological control (Lyman, 1982).

Data from free-ranging echidnas in the wild have shown that hibernation in the echidna closely resembles hibernation in other mammals, with body temperature $\left(T_{\mathrm{b}}\right)$ following a pattern identical to that of eutherian mammals (Grigg et al., 1989; Beard et al., 1992; Nicol and Andersen, 1996, 2000). During hibernation body temperature drops to within about $1{ }^{\circ} \mathrm{C}$ of ambient $\left(T_{\mathrm{a}}\right)$, down to about $5{ }^{\circ} \mathrm{C}$, and the period of hibernation

\footnotetext{
2 Presented as part of the Russell V. Baudinette Memorial Symposium held in Adelaide, Australia, 1-2 October 2005.

* Corresponding author. Tel.: +61 3 6226262678; fax: +61 362262679 .

E-mail address: s.c.nicol@utas.edu.au (S.C. Nicol).
}

is broken by periodic arousals with euthermic periods lasting about 1 day (Nicol and Andersen, 2000).

In eutherian hibernators the heat for rewarming is generated in brown adipose tissue (BAT), which appears so important for arousal from hibernation that Cannon and Nedergaard (2004) in their review of BAT state "brown fat-derived heat is essential for arousal from hibernation in mammals". However, Hayward and Lisson (1992) after examining tissues from all extant families of marsupials and monotremes concluded that BAT is unique to eutherian mammals, and examination of tissue samples from echidnas has also failed to reveal expression of UCP1 (Kabat and Andersen, unpublished data). Thus all evidence indicates that the echidna, like marsupials, does not have BAT, or BATlike function, reinforcing the fact that BAT based thermogenesis is not a prerequisite for arousal from torpor (Körtner and Geiser, 2000).

Given the importance of BAT to eutherian hibernators for arousal from hibernation it is of considerable interest to compare warm-up rates of eutherian and non-eutherian hibernators. In a comprehensive study Geiser and Baudinette (1990) compared maximal rewarming rates at $T_{\mathrm{a}}$ of about $20^{\circ} \mathrm{C}$ for eutherian and marsupial hibernators and the echidna. They found no difference between marsupials and eutherian mammals, and suggested that rewarming rates for echidnas were no 


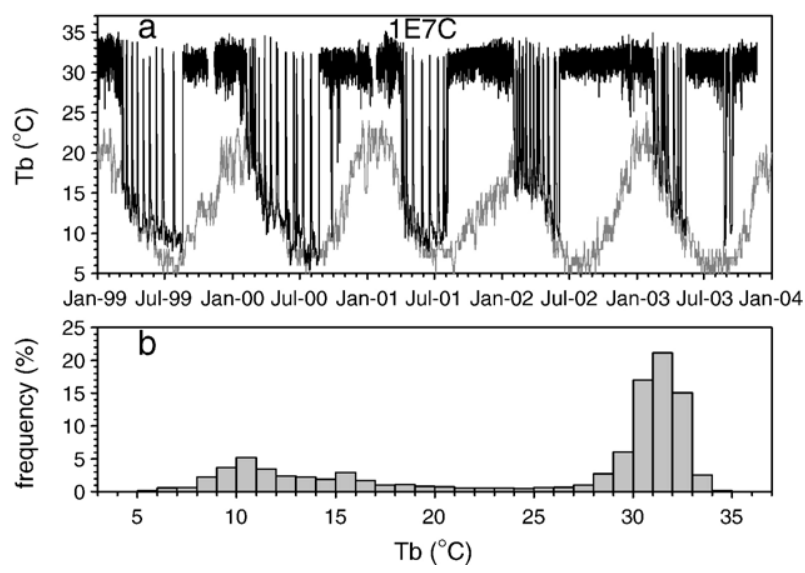

Fig. 1. (a) $T_{\mathrm{b}}$ data (black lines) recorded from an adult male echidna (1E7C, average mass $3.9 \mathrm{~kg}$, mass range $3.2-5.2 \mathrm{~kg}$ ) from January 1999 until November 2003. Gaps in the record represent the point at which loggers were exchanged, and the recovery period in which the echidna was held in captivity. Grey line shows soil temperature measured at a depth of $20 \mathrm{~cm}$. The lower panel (b) shows the frequency distribution of the entire $T_{\mathrm{b}}$ data set for this echidna.

lower than those for other mammals. Stone and Purvis (1992) analysed a smaller data set from eutherian and marsupial heterotherms showing torpor (minimum $T_{\mathrm{b}}$ of about $20{ }^{\circ} \mathrm{C}$, maximum body mass $230 \mathrm{~g}$ ) whereas Geiser and Baudinette (1990) found maximal metabolic rate to be positively correlated with basal metabolic rate (BMR). Stone and Purvis (1992) claimed a negative correlation between mean rewarming rate and BMR, but a positive correlation between peak warm-up rate and BMR. Neither study found a difference between rewarming rates of eutherians and marsupials, and both suggested that an absence of brown fat did not affect rewarming ability.

Because it is very difficult to induce echidnas to hibernate in the laboratory, we have for the last 10 years concentrated on studying hibernation in echidnas in the field, by using implanted temperature data-loggers in free-ranging echidnas (Nicol and Andersen, 1996, 2000, 2002; Nicol et al., 2004) and we have so far collected more than 39 echidna years of data from 14 animals. These data include a large number of arousals, and the principal aim of this paper is to investigate the rewarming rates of free-ranging animals under natural conditions and to compare these with published data from laboratory measurements. A data set of this size is also amenable to analyses that could not be carried out by collecting $T_{\mathrm{b}}$ data manually, and we thus asked the question: "Is it possible to make inferences about the nature of thermogenesis in echidnas from this data?"

\section{Materials and methods}

Fourteen echidnas (Tachyglossus aculeatus, 9 adult female, 4 adult male and one juvenile male) were caught by hand at our field study site in the southern Tasmanian midlands, and brought to the University of Tasmania. Temperature dataloggers (Stowaway Tidbit, Onset Computer Corporation) were implanted intraperitoneally under halothane or isoflurane anaesthesia, and a tracking transmitter was glued to the spines on the lower back. After a recovery period the echidnas were returned to their site of capture.

The loggers have a measurement range of $-5-37^{\circ} \mathrm{C}$, a stated accuracy of $\pm 0.2{ }^{\circ} \mathrm{C}$, and resolution of $0.16^{\circ} \mathrm{C}$. Loggers were coated in a wax-polymer compound (Elvax, Dupont) to improve water resistance and prevent tissue reactions. The final package (mass approximately $25 \mathrm{~g}$ ) was slightly larger than the $30 \times 41 \times 17 \mathrm{~mm}$ logger, and the $95 \%$ response time of the packaged logger to a step change of $10^{\circ} \mathrm{C}$ was about $7 \mathrm{~min}$ in a stirred water bath and $8 \mathrm{~min}$ in an unstirred bath. Initially $8 \mathrm{~K}$ loggers were used but for later measurements we used $32 \mathrm{~K}$ loggers capable of recording $T_{\mathrm{b}}$ hourly for 3.7 years. To extend the recording period for the $8 \mathrm{~K}$ loggers the sampling interval for field recording was set to $96 \mathrm{~min}$ in some cases, but for the majority of the recordings the sampling interval was $1 \mathrm{~h}$. Loggers were calibrated before implantation and after removal. In only one case did we find a significant deviation from the specified calibration that required correction. One echidna (male 1E7C) was subsequently fitted with an activity logger (Minimitter Actiwatch) (Nicol et al., 2004), giving 6 months of concurrent $T_{\mathrm{b}}$ and activity records. Meteorological data, including soil temperature data $\left(T_{\text {soil }}\right)$ measured at a depth of $20 \mathrm{~cm}$, was obtained from an Australian Bureau of Meteorology observation station on the field site within a few $\mathrm{km}$ of the animals.

\section{Results and data analysis}

Details of the timing and patterns of hibernation based on some of these data have been published previously (Nicol and Andersen, 2002). Figs. 1 and 2 show two of the largest $T_{\mathrm{b}}$ data sets. Fig. 1 shows $T_{\mathrm{b}}$ data recorded from an adult male echidna (1E7C, average weight $3.9 \mathrm{~kg}$, weight range $3.2-5.2 \mathrm{~kg}$ ) from January 1999 until November 2003, representing a total of $35,763 T_{\mathrm{b}}$ data points or 1962 days of data. Gaps in the record represent the point at which loggers were exchanged, and the recovery period in which the echidna was held in captivity. Fig. 2 is a recording from a female echidna (5D5E, average weight $3.8 \mathrm{~kg}$, range $3.5-4.2 \mathrm{~kg}$ ) from January 1997 until November 2001 (37,389 data points, 1697 days). Also shown

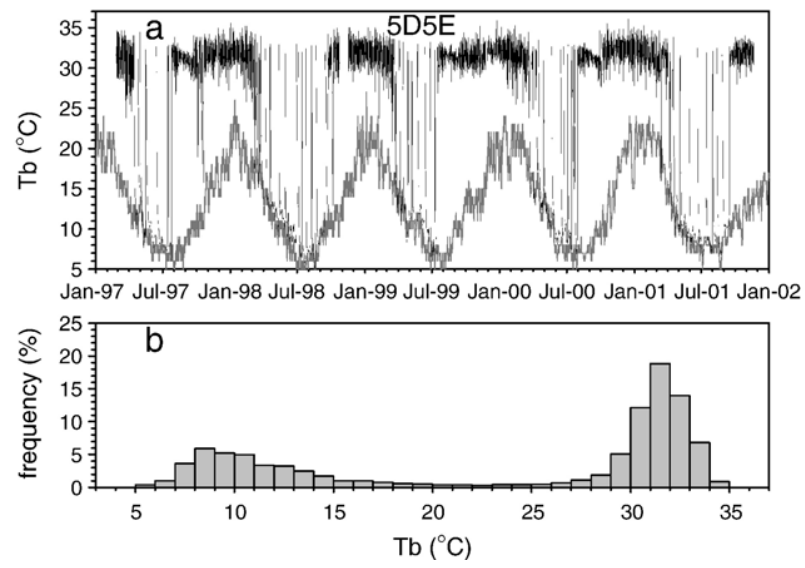

Fig. 2. $T_{\mathrm{b}}$ of a female echidna (5D5E, average mass $3.8 \mathrm{~kg}$, range $3.5-4.2 \mathrm{~kg}$ ) from January 1997 until November 2001. Other details as in Fig. 1. 
Table 1

Summary of body temperature data from 14 Tasmanian echidnas (Tachyglossus aculeatus setosus) implanted with temperature loggers

\begin{tabular}{lc}
\hline Total record length (days) & $1020 \pm 744(263-2291), n=14$ \\
Mass $(\mathrm{kg})$ & $3.6 \pm 0.6(2.4-4.7), n=14$ \\
$T_{\mathrm{bmax}}\left({ }^{\circ} \mathrm{C}\right)$ & $35.3 \pm 0.7(34.3-36.7), n=14$ \\
$T_{\mathrm{b} \min }\left({ }^{\circ} \mathrm{C}\right)$ & $6.3 \pm 1.5(4.7-9.1), n=14$ \\
$T_{\mathrm{b}}>34{ }^{\circ} \mathrm{C}(\%)$ & $0.7 \pm 0.7(0.1-2.6), n=14$ \\
$\mathrm{~d} T_{\mathrm{b}} / \mathrm{d} t_{\max }\left({ }^{\circ} \mathrm{C} \mathrm{h}{ }^{-1}\right)$ & $7.2 \pm 0.8(5.9-8.3), n=12$ \\
$T_{\mathrm{b}}$ at $\mathrm{d} T_{\mathrm{b}} / \mathrm{d} t_{\max }\left({ }^{\circ} \mathrm{C}\right)$ & $26.2 \pm 2.4(23.5-30.8), n=12$ \\
\hline
\end{tabular}

Data for 8 echidnas are derived from single logger records (263-1348 days), for one echidna the data are based on two records, and for the remaining 6 echidnas, on 4 separate logger records each. Peak warming rates $\left(\mathrm{d} T_{\mathrm{b}} / \mathrm{d} t_{\max }\right)$ are based on 60 min sampling intervals only. All values are shown as mean \pm S.D. and range; $n$ : number of animals.

on these graphs is soil temperature measured at a depth of $20 \mathrm{~cm}$. Figs. $1 \mathrm{~b}$ and $2 \mathrm{~b}$ show the frequency distribution of the entire $T_{\mathrm{b}}$ data set for each animal. These graphs show the timing of the annual hibernation, the length of which may vary from year to year ((Nicol and Andersen, 2002). The unusual pattern for echidna 1E7C in 2003 is due to it being disturbed during changeover of the activity logger in May, and then re-entering hibernation in August. 5D5E shows the characteristic flattening of the post-hibernation $T_{\mathrm{b}}$ record in 1997, 1999, and 2000 associated with reproductive activity (Nicol et al., 2005, Nicol and Andersen, 2006), and which is followed in 1997 by a reentry into hibernation apparently after losing the pouch young. Data from all 14 echidnas are summarised in Table 1.

\subsection{Euthermic $T_{b}$}

Figs. $1 \mathrm{~b}$ and $2 \mathrm{~b}$ show that for the majority of time, when not hibernating, echidnas maintain $T_{\mathrm{b}}$ in the range $30-33{ }^{\circ} \mathrm{C}$. The frequency distribution of temperatures is essentially as described by Grigg et al. (1992). The modal $T_{\mathrm{b}}$ range for 10 of the 14 echidnas was $31-32^{\circ} \mathrm{C}, 32-33^{\circ} \mathrm{C}$ for 3 echidnas, and $30-31{ }^{\circ} \mathrm{C}$ for the other. For the data shown in Fig. 1, excluding the periods of torpor or hibernation, the mean $T_{\mathrm{b}}$ is $31.2 \pm$ $1.3{ }^{\circ} \mathrm{C}$, the mean daily $T_{\mathrm{b}}$ range is $2.4 \pm 1.0^{\circ} \mathrm{C}$, and $98 \%$ of the data lies between 28 and $34{ }^{\circ} \mathrm{C}$. The large daily variation in $T_{\mathrm{b}}$ is associated with activity, with maxima of both normally occurring at night (Brice et al., 2002; Nicol et al., 2004). Figs. 1a and $2 \mathrm{a}$ show that $T_{\mathrm{b}}$ rarely exceeds $34{ }^{\circ} \mathrm{C}$; for all echidnas this was only $0.7 \%$ of recording time (Table 1 ). In the total of 14,281 days of $T_{\mathrm{b}}$ record there were only 3 data points in which $T_{\mathrm{b}}$ exceeded $36^{\circ} \mathrm{C}$. On each occasion this was a single spike in $T_{\mathrm{b}}$ on a warm day in February after the echidna had shown a pre-hibernatory reduction in $T_{\mathrm{b}}$. Entry into hibernation follows a reduction and then complete abolition of the daily activity cycle (Nicol et al., 2004).

\subsection{Hibernating $T_{b}$}

Figs. 1, 2 and 3 show that during hibernation the minimum $T_{\mathrm{b}}$ closely follows soil temperature $\left(T_{\text {soil }}\right)$. It is important to note that this measurement was made several $\mathrm{km}$ from where the echidnas were hibernating, and that during hibernation Tasmanian echidnas bury themselves in soil, in piles of leaves and bark, under grass tussocks or rocks, or inside hollow logs or stumps (Andersen and Nicol, unpublished observation). However our results indicate that soil temperature at $20 \mathrm{~cm}$ is a good measure of the conditions to which a hibernating echidna is exposed. The differences between the distributions of $T_{\mathrm{b}}$ below the euthermic range in Figs. $1 \mathrm{~b}$ and $2 \mathrm{~b}$ reflect the fact the male echidna (1E7C) entered hibernation earlier in the year and aroused earlier than the female (5D5E), and thus was equilibrated with higher substrate temperatures. The lowest $T_{\mathrm{b}}$ recorded in the field (Table 1) was $4.7^{\circ} \mathrm{C}$, recorded in 3 echidnas, which is close to the minimum of $4.5{ }^{\circ} \mathrm{C}$ recorded in the laboratory (Nicol and Andersen, 1993). Grigg et al. (1992) reported a minimum $T_{\mathrm{b}}$ of $3.7^{\circ} \mathrm{C}$ at Mt Kosciuszko at a $T_{\mathrm{a}}$ of $0.8^{\circ} \mathrm{C}$, but this was calculated from the pulse rate of a $T_{\mathrm{b}}$ transmitter recorded on a tape recorder, which is subject to a number of significant potential errors, particularly at low temperatures.

\subsection{Rewarming rates}

Rates of change of $T_{\mathrm{b}}\left(\mathrm{d} T_{\mathrm{b}} / \mathrm{d} t\right)$ were calculated by taking the difference between consecutive readings, and it was assumed that this rate occurred at the mid-point between $T_{\mathrm{b}}$ readings. Fig. 3a shows 12 months of the recording from Fig. 2 and in Fig. $3 \mathrm{~b} \mathrm{~d} T_{\mathrm{b}} / \mathrm{d} t$ is plotted on the same time scale. In this graph the highest warming rates occur during the periodic arousals. A comparison of results from loggers sampling at 60 and $92 \mathrm{~min}$ intervals showed that the calculated maximum rewarming rates were lower at the longer sampling interval $\left(6.2 \pm 0.6{ }^{\circ} \mathrm{C} \mathrm{h}{ }^{-1}\right.$, $n=8$ at $92 \mathrm{~min}$, cf. $7.1 \pm 0.7{ }^{\circ} \mathrm{C} \mathrm{h}^{-1}, n=19$ at $60 \mathrm{~min} ; t=3.2$, $p=0.003$ ), and thus only data collected at $60 \mathrm{~min}$ intervals were used for analyses of peak rates. To further clarify the effect of sampling rate on the calculated peak rewarming rate we fitted a sigmoid curve to one arousal event, and then investigated the effect of different sampling rates on the estimated maximum. At a $1 \mathrm{~h}$ sampling interval, the worst case was a $10 \%$ underestimate of $\mathrm{d} T_{\mathrm{b}} / \mathrm{d} t_{\max }$, and thus we believe that our data are realistic and that a sampling interval of $1 \mathrm{~h}$ is adequate for echidnas.

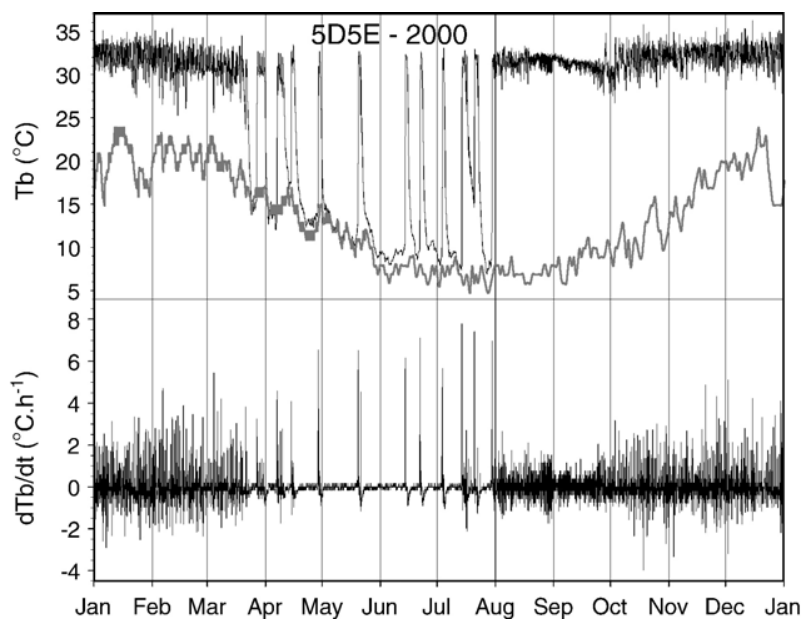

Fig. 3. 12 months of the $T_{\mathrm{b}}$ and soil temperature data from Fig. 2, with the lower panel showing rate of change of body temperature $\left(\mathrm{d} T_{\mathrm{b}} / \mathrm{d} t\right)$ plotted on the same time scale. 

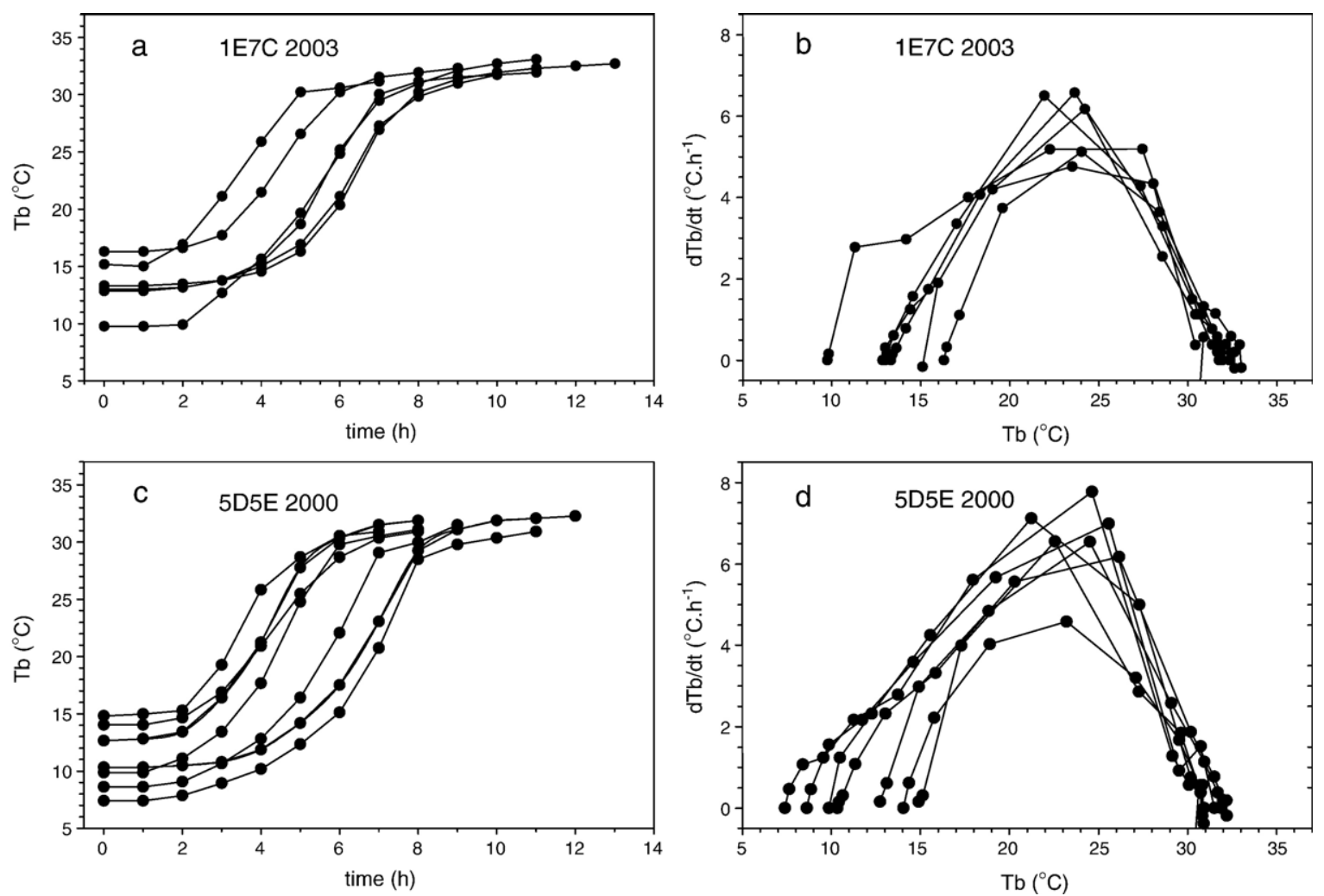

Fig. 4. Arousal events from echidna 1E7C during February-May 2003 (upper panels) and echidna 5D5E during March-August 2000 (lower panels). The figures on the left show $T_{\mathrm{b}}$ plotted as a function of time from the first rise in $T_{\mathrm{b}}$, and on the right, the same arousals are shown with $\mathrm{d} T_{\mathrm{b}} / \mathrm{d} t$ plotted as a function of $T_{\mathrm{b}}$. As the starting $T_{\mathrm{b}}$ is in equilibrium with $T_{\mathrm{a}}$, these figures show that maximum rewarming rates are not affected by $T_{\mathrm{a}}$.

Fig. 4 shows arousal events from echidnas $1 \mathrm{E} 7 \mathrm{C}$ and 5D5E during February-May 2003, and March-August 2000, respectively. The figures and analyses only include uninterrupted arousals from stable hibernation, i.e. the echidnas were thermoconforming before arousal, and the arousal was uninterrupted. We have taken the starting point as the $T_{\mathrm{b}}$ before the first increase in $T_{\mathrm{b}}$, and the end point as the last point at which $T_{\mathrm{b}}$ was still increasing. When $\mathrm{d} T_{\mathrm{b}} / \mathrm{d} t$ is plotted against $T_{\mathrm{b}}$ (Fig. $4 \mathrm{~b}$ and $\mathrm{d}$ ) it can be seen that the highest rates of rewarming occur in the range $21-27^{\circ} \mathrm{C}$. For the 12 echidnas in which $T_{\mathrm{b}}$ was recorded at hourly intervals, the $T_{\mathrm{b}}$ at peak rewarming was 31 rewarming episodes from 4 echidnas where initial $T_{\mathrm{b}}<17{ }^{\circ} \mathrm{C}$ (i.e. the echidnas were thermoconforming) showed a weak but significant negative correlation between initial $T_{\mathrm{b}}$ and arousal time (rewarming time $=15.6-0.41 T_{\text {initial }}$; $\left.r^{2}=0.26, p=0.003, n=31\right)$. Average rewarming time in these episodes was $10.8 \pm 2.2 \mathrm{~h}(n=31)$ from an initial $T_{\mathrm{b}}$ of $11.7 \pm$ $2.7^{\circ} \mathrm{C}$, giving an average rewarming rate of $1.9 \pm 0.4{ }^{\circ} \mathrm{C} \mathrm{h}^{-1}$. Including arousals from high $T_{\mathrm{b}} \mathrm{s}$ where the echidnas were not thermoconforming did not significantly change the regression coefficients, but did increase the correlation coefficient (rewarming time $=16.0-0.44 T_{\text {initial }} ; r^{2}=0.70, p<0.0001$, $n=43$ ).

Analysis of this data also shows that initial $T_{\mathrm{b}}$, which reflects $T_{\mathrm{a}}$, does not affect maximal rewarming rate. Overall there was a negative, but non-significant relationship between initial $T_{\mathrm{b}}$ and maximal rate $\left(r^{2}=0.07, p=0.08, n=43\right)$.

\section{Discussion}

\subsection{Rewarming from deep torpor}

As Stone and Purvis (1992) point out, mean rewarming rate and peak rewarming rate are quite different ways of describing rewarming; mean rewarming rates are useful in considering the energetics of arousal as a whole, whereas peak rewarming rate is more a measure of the maximum thermogenic capacity of the animal.

The field data show that peak rewarming rates of echidnas $\left(7.2 \pm 0.8{ }^{\circ} \mathrm{C} \mathrm{h}^{-1}\right.$, Table 1) are much greater than the rate measured by Augee and Ealey (1968) of $2.2^{\circ} \mathrm{C} \mathrm{h}^{-1}$, which was used in the analysis of Geiser and Baudinette (1990). However, this rate came from a study where torpor was induced by starvation, which would have depleted energy reserves, whereas natural hibernation in echidnas occurs after they have laid down significant fat stores (Falkenstein et al., 2001). These rates are also higher than those recorded in laboratory studies of normally hibernating echidnas $\left(3-5^{\circ} \mathrm{C} \mathrm{h}^{-1}\right.$, Nicol et al., 1992).

All analyses have shown that mass is a major determinant of rewarming rates, which is a particularly important consideration when comparing echidnas with other hibernating species, as echidnas lie at the extreme end of the hibernating weight range. For example, in the analysis by Geiser and Baudinette (1990) the echidna lies more than 2 standard deviations from the mean of the $\log$ weights. Thus although the regression derived by Geiser 


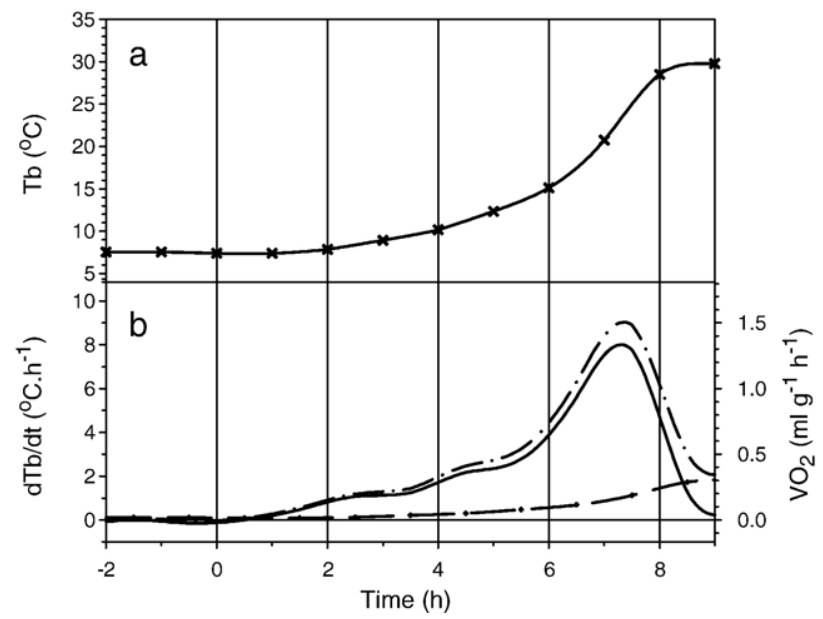

Fig. 5. A single rewarming episode from Fig. 4c, with $\mathrm{d} T_{\mathrm{b}} / \mathrm{d} t$ plotted against the same time scale (solid line, lower panel). The right hand axis shows the oxygen consumption equivalent of the heating rate. Also shown is calculated heat loss (broken lines) and total heat production (dot-dash lines).

and Baudinette (1990) from all mammalian data predicts a value of $7.0{ }^{\circ} \mathrm{C} \mathrm{h}^{-1}$ at a mass of $3.6 \mathrm{~kg}$, which is very close to the average echidna maximum rewarming rate in Table 1 (7.2 \pm $0.8^{\circ} \mathrm{C} \mathrm{h}^{-1}$ ) the lower and upper $95 \%$ prediction intervals are 2.6 and $20.1{ }^{\circ} \mathrm{C} \mathrm{h}^{-1}$, respectively. The only mammals which show deep hibernation and which are of comparable mass to echidnas are marmots, but even then it is important to ensure that consistent criteria are used. Fig. 4a and c clearly demonstrate that rewarming follows a sigmoid curve (Stone and Purvis, 1992), and thus that rewarming models that assume linear warming e.g. McKechnie and Wolf (2004) are an oversimplification. We assume that the sigmoid shape of the rewarming curve is due to an exponential increase in reaction rate as $T_{\mathrm{b}}$ rises, in accordance with Bolzmann's factor (Gillooly et al., 2001), combined with a reduction in thermoregulatory drive as $T_{\mathrm{b}}$ approaches the euthermic range. The sigmoid shape of the rewarming curve means that it may be difficult to determine where warming begins and ends, which can have a significant effect on estimated rewarming times, and average rewarming rates. For example, rewarming time in communally hibernating $4 \mathrm{~kg}$ alpine marmots (Marmota marmota) was calculated to be $9.1 \pm 1.1 \mathrm{~h}$, with a mean heating rate of $2.2 \pm 0.4{ }^{\circ} \mathrm{C} \mathrm{h}^{-1}$ (Ruf and Arnold, 2000), which is not significantly faster than the $10.8 \pm 2.2 \mathrm{~h}$ rewarming and average rewarming rate of $1.9 \pm 0.4{ }^{\circ} \mathrm{C} \mathrm{h}^{-1}$ found for echidnas. However, for free-ranging woodchucks (Marmota monax, mean mass $3.2 \mathrm{~kg}$ ) calculated rewarming time was only $4.3 \pm 1.6 \mathrm{~h}$, and rewarming rate was $6.0 \pm 0.9{ }^{\circ} \mathrm{C} \mathrm{h}^{-1}$ (Zervanos and Salsbury, 2003). The apparently faster rewarming of the woodchucks than the alpine marmots may be partly attributed to a higher burrow temperature and higher initial $T_{\mathrm{b}}$, and the fact that rewarming time was calculated as the time taken for $T_{\mathrm{b}}$ to reach $30{ }^{\circ} \mathrm{C}$. However, a preliminary re-analysis of raw data from the study of Ruf and Arnold (2000), with $\mathrm{d} T_{\mathrm{b}} / \mathrm{d} t$ calculated in the same way as for the echidnas, yielded peak rewarming rates approximately twice those of echidnas. We expect that a similar standardised calculation for woodchucks would yield comparable rewarming rates to marmots.

\subsection{Metabolic rates during rewarming}

The total amount of energy used by the animal between any two $T_{\mathrm{b}}$ measurements must equal the increase in heat content of the animal plus heat lost to the environment. The increase in heat content, $\Delta Q$, as $T_{\mathrm{b}}$ rises from $T_{0}$ to $T_{1}=c\left(T_{1}-T_{0}\right) M_{\mathrm{b}}$, where $c$ is the specific heat of animal tissues and $M_{\mathrm{b}}$ is body mass. The specific heat of tissue is usually taken to be $3.48 \mathrm{~J} \cdot \mathrm{g}^{-1} \cdot{ }^{\circ} \mathrm{C}^{-1}$ (IUPS Thermal Commission, 2001), but as echidnas typically will have 25-35\% body fat (Green et al., 1992) which has a specific heat of $2.97 \mathrm{~J} \mathrm{~g}^{-1}{ }^{\circ} \mathrm{C}^{-1}$, we have used a lower average specific heat for echidna tissue of $3.35 \mathrm{~J} \mathrm{~g}^{-1}{ }^{\circ} \mathrm{C}^{-1}$. Assuming an energy equivalent of oxygen of $20.1 \mathrm{~J} \mathrm{ml}^{-1}$, a rise in $T_{\mathrm{b}}$ of $1{ }^{\circ} \mathrm{C}$ per hour at this specific heat is equivalent to $0.167 \mathrm{ml} \mathrm{O}_{2} \mathrm{~g}^{-1} \mathrm{~h}^{-1}$. Fig. 5 shows a single rewarming episode from Fig. 4 , with $\mathrm{d} T_{\mathrm{b}} / \mathrm{d} t$ plotted against time (solid line). The right hand axis shows the oxygen consumption equivalent of the heating rate.

Heat lost to the environment during rewarming, when the animal is normally sheltered from wind, evaporative cooling, or radiant heating, can be simply calculated from the ScholanderIrving equation: $\dot{\mathrm{V}} \mathrm{O}_{2}=k\left(T_{\mathrm{b}}-T_{\mathrm{a}}\right)$, where $T_{\mathrm{a}}$ is ambient temperature, and $k$ is thermal conductance. If we assume that thermal conductance during hibernation is the same as the minimum value measured during cold exposure $\left(0.013 \pm 0.0005 \mathrm{ml} \mathrm{O}_{2} \mathrm{~g}^{-1} \mathrm{~h}^{-1}\right.$ ${ }^{\circ} \mathrm{C}^{-1}$ in the Tasmanian sub-species (McNab, 1984), an assumption that is supported by estimating conductance from

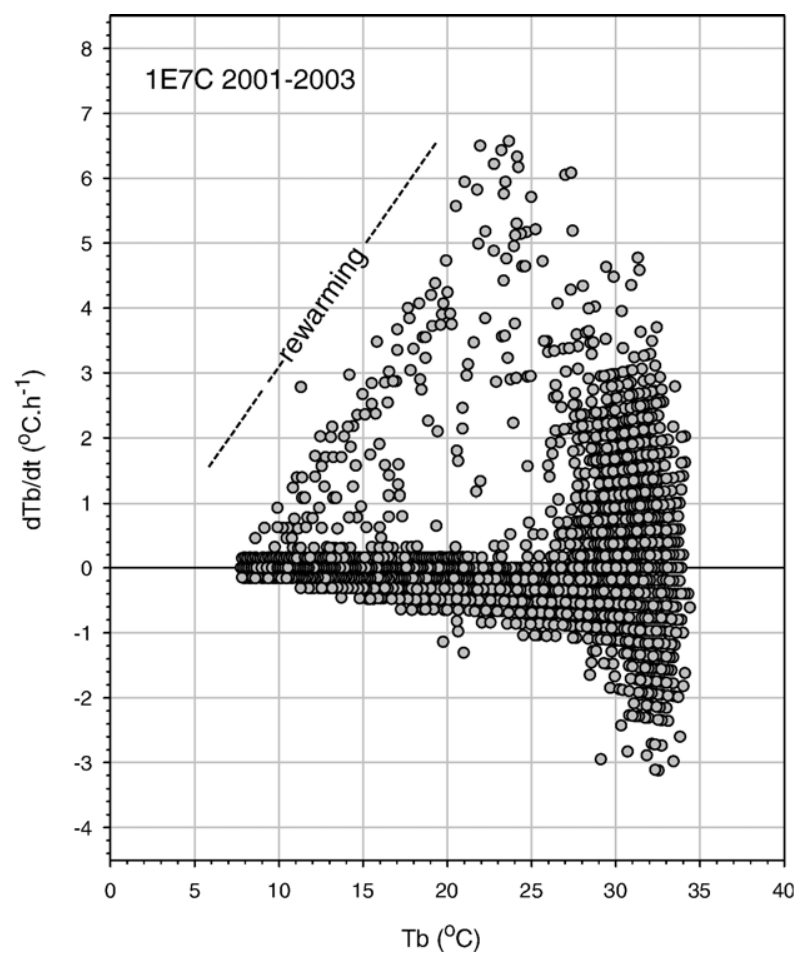

Fig. 6. Data from 2001 to 2003 from Fig. 1 replotted showing $\mathrm{d} T_{\mathrm{b}} / \mathrm{d} t$ as a function of $T_{\mathrm{b}}$. This represents 1031 days of $T_{\mathrm{b}}$ data recorded at hourly intervals. (Earlier data in Fig. 1 were collected at 92 min intervals.) Positive values of $\mathrm{d} T_{\mathrm{b}} /$ $\mathrm{d} t$ are warming, negative values are cooling. The figure shows that the warming rate during periodic arousals is dependent on $T_{\mathrm{b}}$, and that in this echidna maximum rewarming rate $\left(6.6^{\circ} \mathrm{C} \mathrm{h}^{-1}\right)$ occurs at $23.6^{\circ} \mathrm{C}$. Fig $4 \mathrm{~b}$ represents a subset of these data. 
cooling rates, and that $T_{\mathrm{a}}$ is $1{ }^{\circ} \mathrm{C}$ below the initial $T_{\mathrm{b}}$ (Geiser, 2004)), it is possible to calculate the heat loss for each $T_{\mathrm{b}}$ point. These calculated values are plotted in Fig 5b, along with the total heat production. For this arousal, the calculated $\dot{\mathrm{VO}}_{2 \max }$ is $1.5 \mathrm{ml}$ $\mathrm{O}_{2} \mathrm{~g}^{-1} \mathrm{~h}^{-1}$. Even at the relatively low $T_{\mathrm{a}}$ for this arousal (estimated to be $6.2{ }^{\circ} \mathrm{C}$ ) nearly all of the heat produced is stored and heat loss to the environment accounts for only $13 \%$ of the peak oxygen consumption. Substitution of different values for the initial $T_{\mathrm{a}}-T_{\mathrm{b}}$ difference and conductance shows the calculated $\dot{\mathrm{V}} \mathrm{O}_{2 \max }$ to be relatively insensitive to variations within the range of likely values. Based on the $\mathrm{d} T_{\mathrm{b}} / \mathrm{d} t_{\max }$ data summarised in Table 1 , mean $\dot{\mathrm{VO}}_{2 \max }$ for these animals would be about $1.4 \pm 0.2 \mathrm{ml} \mathrm{O}_{2}$ $\mathrm{g}^{-1} \mathrm{~h}^{-1}\left(1.1-1.6 \mathrm{ml} \mathrm{O}_{2} \mathrm{~g}^{-1} \mathrm{~h}^{-1}\right)$, approximately 9 times the BMR $\left(0.15 \pm 0.01 \mathrm{ml} \mathrm{g}^{-1} \mathrm{~h}^{-1}\right)$ (McNab, 1984). This is consistent with the $\dot{\mathrm{VO}}_{2 \max }$ values of $0.8-1.2 \mathrm{ml} \mathrm{g}^{-1} \mathrm{~h}^{-1}$ measured in $2.2 \mathrm{~kg}$ echidnas in laboratory studies at a $T_{\mathrm{a}}$ of $5{ }^{\circ} \mathrm{C}$, where the highest rewarming rates were $3-5^{\circ} \mathrm{C} \mathrm{h}^{-1}$ (Nicol et al., 1992; Nicol and Andersen, 1993), and $1.3 \mathrm{ml} \mathrm{g}^{-1} \mathrm{~h}^{-1}$ measured during treadmill exercise (Hinds et al., 1993; Andersen and Nicol, unpublished observations). During rewarming, high rates of metabolism, i.e. rates in excess of normal field metabolic rate (approx. $0.5 \mathrm{ml} \mathrm{O}_{2}$ $\mathrm{g}^{-1} \mathrm{~h}^{-1}$, Schmid et al., 2003) appear to last about $3 \mathrm{~h}$ (Fig. 5).

\subsection{A new graphical analysis and mechanisms of thermogenesis}

Extracting data for rewarming rates for individual arousals (Fig. $4 \mathrm{~b}$ and d) is a relatively time consuming process. In Figs. 6

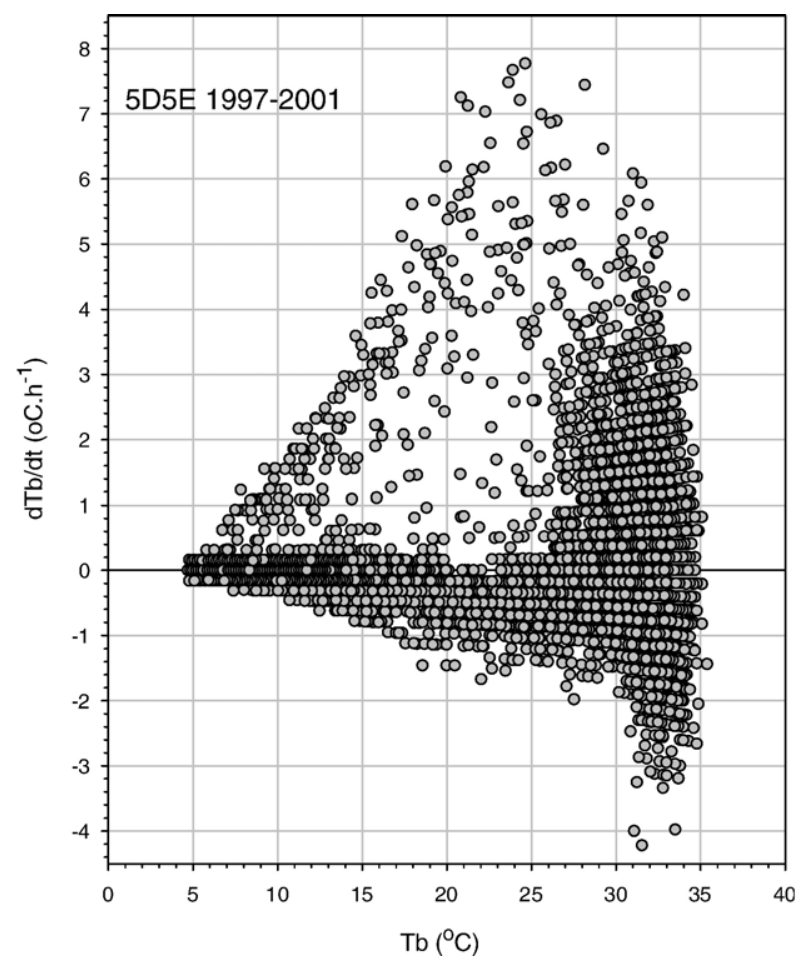

Fig. 7. Data from Fig. 2 replotted showing $\mathrm{d} T_{\mathrm{b}} / \mathrm{d} t$ as a function of $T_{\mathrm{b}}$. This represents 1289 days of $T_{\mathrm{b}}$ data recorded at hourly intervals. Data from November 1998 to December 1999 have not been included as they were collected at $92 \mathrm{~min}$ intervals. In this echidna maximum rewarming rate $\left(7.8^{\circ} \mathrm{C}\right.$ $\mathrm{h}^{-1}$ ) occurs at $24.6^{\circ} \mathrm{C}$. Fig $4 \mathrm{~d}$ represents a subset of these data.

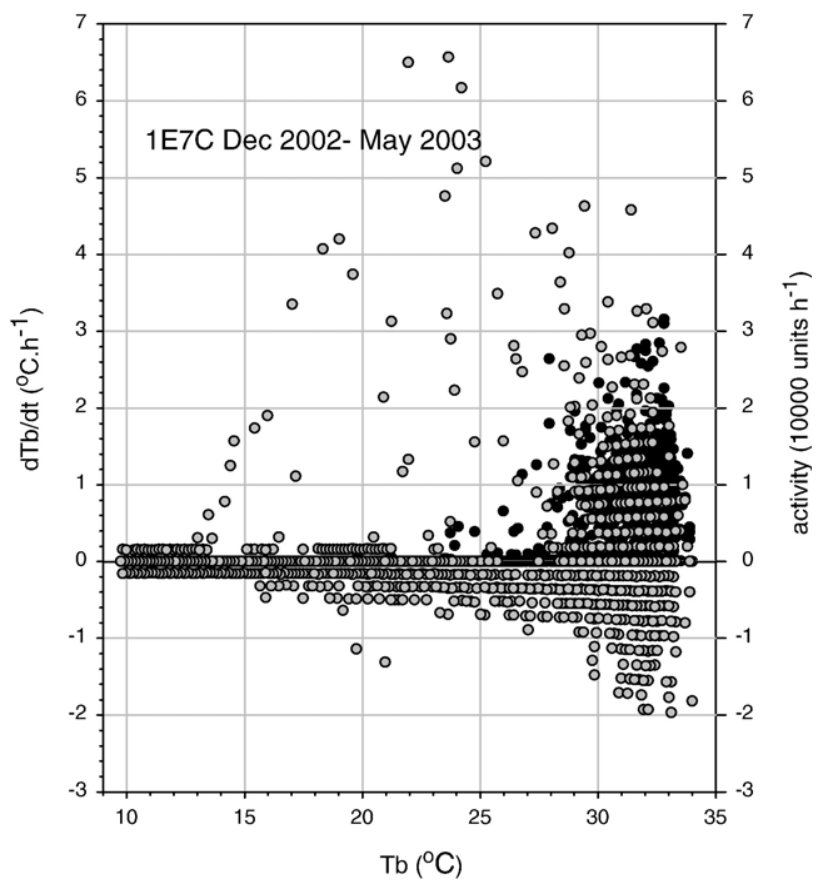

Fig. 8. Six months of $\mathrm{d} T_{\mathrm{b}} / \mathrm{d} t$ data from echidna $1 \mathrm{E} 7 \mathrm{C}$, when it was fitted with an activity logger, overlaid on activity data (solid symbols) recorded at the same time, with both plotted against $T_{\mathrm{b}}$. This figure shows that the solid blocks of data points on the right of Figs. 6 and 7 are associated with activity.

and 7, the data from Figs. 1 and 2 have been replotted, with $\mathrm{d} T_{\mathrm{b}} / \mathrm{d} t$ plotted against $T_{\mathrm{b}}$. The points in the upper left quadrant of the figure correspond to the data on the left of Fig. $4 \mathrm{~b}$, i.e. rewarming up to $\mathrm{d} T_{\mathrm{b}} / \mathrm{d} t_{\max }$, and clearly shows the relationship between rewarming rate and $T_{\mathrm{b}}$. All $\mathrm{d} T_{\mathrm{b}} / \mathrm{d} t$ values above the zero line are by definition warming, and the block of warming data on the right of Figs. 6 and 7 represents rises in $T_{\mathrm{b}}$ associated with the daily activity cycle, as is clear from Fig. 8 , where $\mathrm{d} T_{\mathrm{b}} / \mathrm{d} t$ data are overlaid on activity data recorded at the same time. These data from the one echidna with an activity logger show there is no significant detectable activity until $T_{\mathrm{b}}>23^{\circ} \mathrm{C}$ with most activity occurring at $T_{\mathrm{b}}>29^{\circ} \mathrm{C}$. This is consistent with observations that shivering is not visible when $T_{\mathrm{b}}$ is below $20{ }^{\circ} \mathrm{C}$ (Grigg et al., 1992), and the lowest $T_{\mathrm{b}}$ observed in active echidnas by Brice et al. (2002) was $23{ }^{\circ} \mathrm{C}$. Thus Figs. $6-8$ suggest that there is a fundamental difference between the heat production during rewarming from hibernation, and the heat production associated with gross activity. Echidnas clearly have a very effective thermogenic mechanism, and given the absence of brown adipose tissue, skeletal muscle, which makes up a large proportion of body mass, and which has a high intrinsic capacity for ATP-splitting (Hohtola, 2004) seems the most likely site of thermogenesis. We can only speculate as to whether this is more likely to be associated with shivering thermogenesis (thermoregulatory muscle tone, rather than "true shivering") or thermogenesis without contractile activity (Di Maria et al., 2002).

\section{Acknowledgements}

We thank Megan Richards, Christina Vedel-Smith, Anna Reye and David Lovell for their invaluable assistance in the 
field, and David Lovell for his assistance with the anaesthetic procedures. We are grateful to the McShane family of Stockman Stud for allowing us to carry out this work on their property. Thanks to Thomas Ruf for providing us with the raw data from his marmot study, and to Fritz Geiser for commenting on the MS. Financial support was provided by the Australian Research Council, the University of Tasmania Internal Research Grant Scheme, and the National Geographic Committee for Research and Exploration. This work was carried out under permit from the Tasmanian Department of Primary Industries, Water and Environment, and the University of Tasmania Animal Ethics Committee, and complies with the Tasmanian Animal Welfare Act (1993) and the Australian Code of Practice for the Care and Use of Animals for Scientific Purposes (2004). Thanks to Tomasz Owerkowicz, Sue Runciman and Roger Seymour for organising the symposium, and thanks to Russell Baudinette for his friendship and leadership in Australian comparative physiology.

\section{References}

Augee, M.L., Ealey, E.H.M., 1968. Torpor in the echidna, Tachyglossus aculeatus. J. Mammal. 49, 446-454.

Beard, L.A., Grigg, G.C., Augee, M.L., 1992. Reproduction by echidnas in a cold climate. In: Augee, M.L. (Ed.), Platypus and Echidnas. Royal Zoological Society NSW, Mosman, pp. 93-100.

Brice, P.H., Grigg, G.C., Beard, L.A., Donovan, J.A., 2002. Patterns of activity and inactivity in echidnas (Tachyglossus aculeatus) free-ranging in a hot dry climate: correlates with ambient temperature, time of day and season. Aust. J. Zool. 50, 461-475.

Cannon, B., Nedergaard, J., 2004. Brown adipose tissue: function and physiological significance. Physiol. Rev. 84, 277-359.

Di Maria, C., Rattigan, S., Clark, M., 2002. Vasoconstrictor-mediated thermogenesis present in perfused skeletal muscle but absent from perfused heart. J. Therm. Biol. 27, 151-158.

Falkenstein, F., Kortner, G., Watson, K., Geiser, F., 2001. Dietary fats and body lipid composition in relation to hibernation in free-ranging echidnas. J. Comp. Physiol. B 171, 189-194.

Geiser, F., 2004. Metabolic rate and body temperature reduction during hibernation and daily torpor. Annu. Rev. Physiol. 66, 239-274.

Geiser, F., Baudinette, R.V., 1990. The relationship between body mass and rate of rewarming from hibernation and daily torpor in mammals. J. Exp. Biol. $151,349-359$

Gillooly, J.F., Brown, J.H., West, G.B., Savage, V.M., Charnov, E.L., 2001. Effects of size and temperature on metabolic rate. Science 293, 2248-2251.

Green, B., Griffiths, M., Newgrain, K., 1992. Seasonal patterns in water, sodium and energy turnover in free-living echidnas, Tachyglossus aculeatus (Mammalia, Monotremata). J. Zool. 227, 351-365.

Grigg, G.C., Augee, M.L., Beard, L.A., 1992. Thermal relations of free-living echidnas during activity and in hibernation in a cold climate. In: Augee, M.L. (Ed.), Platypus and Echidnas. Royal Zoological Society of New South Wales, Mosman, pp. 160-173.

Grigg, G.C., Beard, L.A., Augee, M.L., 1989. Hibernation in a monotreme, the echidna Tachyglossus aculeatus. Comp. Biochem. Physiol. A 92, 609-612.

Hayward, J., Lisson, P., 1992. Evolution of brown fat: its absence in marsupials and monotremes. Can. J. Zool. 70, 171-179.

Hinds, D.S., Baudinette, R.V., Macmillen, R.E., Halpern, E.A., 1993. Maximum metabolism and the aerobic factorial scope of endotherms. J. Exp. Biol. 182, $41-56$.
Hohtola, E., 2004. Shivering thermogenesis in birds and mammals. In: Barnes, B.M., Carey, H.V. (Eds.), Life in the Cold. Evolution, mechanisms, adaptation, and application, University of Alaska Fairbanks, Institute of Arctic Biology, Fairbanks, Alaska, pp. 241-252.

IUPS Thermal Commission, 2001. Glossary of terms for thermal physiology (reprinted from the Japanese J Physiology). J. Therm. Biol. 28, 75-106.

Körtner, G., Geiser, F., 2000. The temporal organization of daily torpor and hibernation: circadian and circannual rhythms. Chronobiol. Int. 17, $103-128$

Lyman, C.P., 1982. Why bother to hibernate? In: Lyman, C.P., Willis, J.S., Malan, A., Wang, L.C.H. (Eds.), Hibernation and Torpor in Mammals and Birds. Academic Press, New York, pp. 1-10.

Martin, C.J., 1902. Thermal adjustment and respiratory exchange in monotremes and marsupials - a study in the development of homoeothermism. Philos. Trans. R. Soc. Lond. Ser. B 195, 1-37.

McKechnie, A.E., Wolf, B.O., 2004. The energetics of the rewarming phase of avian torpor. In: Barnes, B.M., Carey, H. (Eds.), Life in the Cold: Evolution, Mechanisms, Adaptation, and Application, Twelfth International Hibernation Symposium. Institute of Arctic Biology, University of Alaska, Fairbanks, Alaska.

McNab, B.K., 1984. Physiological convergence amongst ant-eating and termiteeating mammals. J. Zool. 203, 485-510 (London).

Nicol, S.C., Andersen, N.A., 1993. The physiology of hibernation in an egglaying mammal, the echidna. In: Carey, C., Florant, G.F., Wunder, B.A., Horwitz, B. (Eds.), Life in the Cold III: Ecological, Physiological, and Molecular Mechanisms. Westview Press, pp. 55-64.

Nicol, S.C., Andersen, N.A., 1996. Hibernation in the echidna: not an adaptation to cold? In: Geiser, F., Hulbert, A.J., Nicol, S.C. (Eds.), Adaptations to the Cold: Tenth International Hibernation Symposium. University of New England Press, Armidale, pp. 7-12.

Nicol, S.C., Andersen, N.A., 2000. Patterns of hibernation of echidnas in Tasmania. In: Heldmaier, G., Klingenspor, M. (Eds.), Life in the Cold: Eleventh International Hibernation Symposium. Springer, Berlin, pp. 21-29.

Nicol, S.C., Andersen, N.A., 2002. The timing of hibernation in Tasmanian echidnas: why do they do it when they do? Comp. Biochem. Physiol. B 131, 603-611.

Nicol, S.C., Andersen, N.A., 2006. Body temperature as an indicator of egglaying in the echidna, Tachyglossus aculeatus. J. Therm. Biol. 31, 483-490.

Nicol, S.C., Andersen, N.A., Jones, S.M., 2005. Seasonal variations in reproductive hormones of free-ranging echidnas (Tachyglossus aculeatus): interaction between reproduction and hibernation. Gen. Comp. Endocrinol. 144, 204-210.

Nicol, S.C., Andersen, N.A., Mesch, U., 1992. Metabolic rate and ventilatory pattern in the echidna during hibernation and arousal. In: Augee, M.L. (Ed.), Platypus and Echidnas. Royal Zoological Society of NSW, pp. 150-159.

Nicol, S.C., Vedel-Smith, C., Andersen, N.A., 2004. Behavior, body temperature and hibernation in Tasmanian echidnas (Tachyglossus aculeatus). In: Barnes, B.M., Carey, H.V. (Eds.), Life in the Cold 2004. Biological Papers of the University of Alaska, Fairbanks, Alaska, pp. 149-157.

Ruf, T., Arnold, W., 2000. Mechanisms of social thermoregulation in hibernating alpine marmots (Marmota marmota). In: Heldmaier, G., Klingenspor, M. (Eds.), Life in the Cold: Eleventh International Hibernation Symposium. Springer, Berlin, pp. 81-94.

Schmid, J., Andersen, N.A., Speakman, J.R., Nicol, S.C., 2003. Field energetics of free-living, lactating and non-lactating echidnas (Tachyglossus aculeatus). Comp. Biochem. Physiol. A 136, 903-909.

Stone, G.N., Purvis, A., 1992. Warm-up rates during arousal from torpor in heterothermic mammals: physiological correlates and a comparison with heterothermic insects. J. Comp. Physiol. B 162, 284-295.

Zervanos, S.M., Salsbury, C.M., 2003. Seasonal body temperature fluctuations and energetic strategies in free-ranging eastern woodchucks (Marmota monax). J. Mammal. 84, 299-310. 